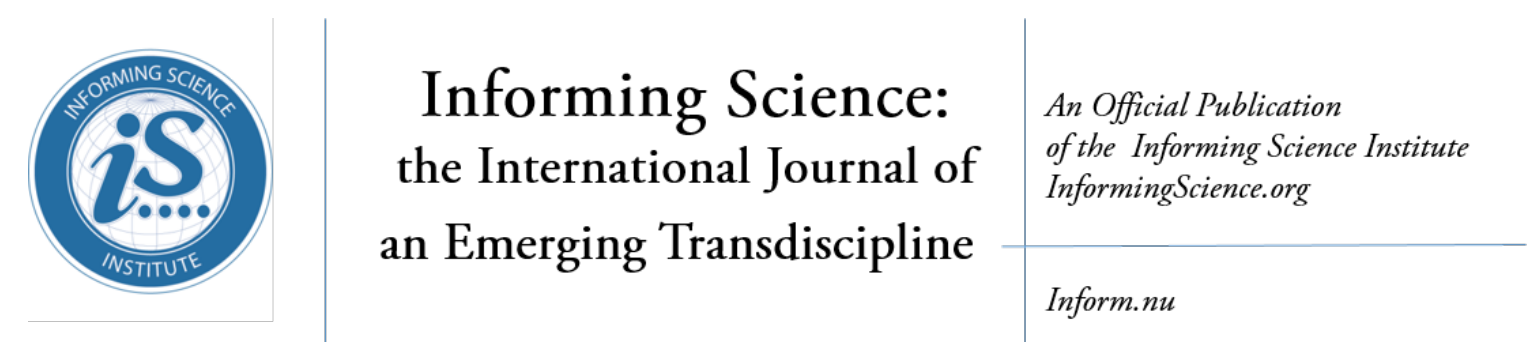

Volume 20, 2017

\title{
FITNESS, EXTRINSIC COMPLEXITY, AND INFORMING SCIENCE
}

$\begin{array}{ll}\text { T. Grandon Gill* } & \begin{array}{l}\text { University of South Florida, Tampa, grandon@usf.edu } \\ \text { Florida, USA }\end{array} \\ \text { Matthew Mullarkey } & \begin{array}{l}\text { University of South Florida, Tampa, mmullarkey@usf.edu } \\ \text { Florida, USA }\end{array} \\ * \text { Corresponding author } & \end{array}$

\section{ABSTRACT}

Aim/Purpose

We establish a conceptually rigorous definition for the widely used but loosely defined term "fitness". We then tie this definition to complexity, highlighting a number of important implications for the informing science transdiscipline.

Background As informing science increasingly incorporates concepts of fitness and complexity in its research stream, rigorous discussion and definition of both terms is essential to effective communication.

Methodology

Our analysis consists principally of a synthesis of past work in the informing science field that incorporates concepts from evolutionary biology, economics and management.

Contribution

We provide a rigorous approach to defining fitness and introduce the construct "extrinsic complexity", as a measure of the amount of information required to predict fitness, to more fully differentiate this form of complexity from other complexity constructs. We draw a number of conclusions regarding how behaviors under low and high extrinsic complexity will differ.

Findings

High extrinsic complexity environments are likely to produce behaviors that include resistance to change, imitation, turbulence and inequality.

Recommendations for Practitioners As extrinsic complexity grows, effective search for problem solutions will in-

Recommendation for Researchers creasingly dominate employing recommended solutions of "best practices".

Impact on Society As extrinsic complexity grows, research tools that rely on decomposing individual effects and hypothesis testing become increasingly unreliable.

We raise concerns about society's continuing investment in academic research that discounts the extrinsic complexity of the domains under study.

Future Research We highlight a need for research to operationalize the concepts of fitness and complexity in practice.

Keywords fitness, complexity, rugged landscapes, punctuated equilibrium, informing

Accepting Editor: Raafat Saadé | Received: December 20, 2016 | Revised: February 12, 2017 | Accepted: February 20, 2017

Cite as: Gill, G., \& Mullarkey, M. (2017). Fitness, extrinsic complexity, and informing science. Informing Science: the International Journal of an Emerging Transdiscipline, 20, 37-61. Retrieved from http://www.informingscience.org/Publications/3668

(CC BY-NC 4.0) This article is licensed it to you under a Creative Commons Attribution-NonCommercial 4.0 International License. When you copy and redistribute this paper in full or in part, you need to provide proper attribution to it to ensure that others can later locate this work (and to ensure that others do not accuse you of plagiarism). You may (and we encourage you to) adapt, remix, transform, and build upon the material for any non-commercial purposes. This license does not permit you to use this material for commercial purposes. 


\section{INTRODUCTION}

A recent stream of research in informing science is built around a conceptual scheme whereby informing is treated as a process through which a client increases fitness on a complex landscape (e.g., see Gill, 2016a and 2016b for a summary). In this research, the meaning of fitness-a term borrowed from evolutionary biology (e.g., Kauffman, 1993) — is more-or-less assumed. The complex landscape model then builds upon that concept, as are the conclusions that we draw from the model. The rigor of this entire research stream is heavily dependent upon one's ability to define fitness in a correspondingly rigorous manner.

In this article, we take a systematic look at the concept of fitness and how it could impact informing processes. To develop this conceptual framework, we start with a model in which an agent or entity is presumed to occupy a position determined by a set of attributes known as a state. That state forms one position in a broader landscape of all possible states. From there, we propose a series of definitions:

1. We define realized fitness as the measurable value that signifies the growth or decline of a collection of entities occupying a set of specific states over a defined period of time.

2. We define the fitness of a state to be the expected value of subsequent realized fitness for all entities occupying that state under all possible scenarios (including those with which we have no means of predicting or measuring an expected value).

3. We define a fitness proxy to be any value that we can measure or observe that we perceive to be closely correlated to the fitness of a state.

4. We define extrinsic complexity to be the amount of information needed to capture the relationship between all possible states in a landscape and their associated fitness values.

With these definitions in place, we then consider how increases in extrinsic complexity are likely to impact the behavior of entities that reside on a fitness landscape. We note that there are two types of potential entities that can be modeled. The first are entities that achieve fitness through selective survival and reproduction across generations, without conscious adaptation (i.e., survival of the fittest). The second are adapting agents, entities that can actively pursue a change in state in order to seek higher fitness. The latter prove to be of particular interest since the decision to become informed represents a particularly important approach to adaptation.

After identifying characteristic behaviors of adapting agents on high extrinsic complexity landscapes, we look at the potential implications for informing. What we find is that achieving effective informing in such circumstances may entail substantially different approaches to the informing process. Indeed, informing techniques built around the groups that naturally form on such landscapes, as opposed to a pure focus on the individual agent, may be required if effective informing is to take place.

\section{WHAT IS FITNESS?}

The term "fitness" is used in many contexts, ranging from models in evolutionary biology (e.g., Kauffman, 1993) to common parlance (e.g., physical fitness, fitness reports). Typically, it refers to some measure of an entities suitability (or "fit") with a particular context. McCarthy (2004, p. 127128) provides a review of the term's origins and identifies a number of management-related applications of the term, including:

organisational development and change (Beinhocker, 1999; McKelvey, 1999; Reuf, 1997), the evolution of organisational structures (Levinthal, 1996), innovation networks in the aircraft industry (Frenken, 2000) and technology selection (McCarthy and Tan, 2000; McCarthy, 2003).

We are by no means alone in noting the fuzziness of fitness. A review of the term's usage in the context of a study of its potential applicability to manufacturing strategy concluded the following (McCarthy, 2004, p. 129): 
Although the term fitness is used regularly in biological and evolutionary publications, its definition and use is unclear. This ambiguity has been transferred to those management and strategy papers that discuss the relevance and insights that fitness landscape theory could offer to management scholars. It seems that most authors assume there is a universally understood meaning of the term and therefore do not provide a working definition.

In choosing not to offer his own precise definition, the same author concludes the following (McCarthy, 2004, p. 131): "Ultimately, the term fitness is used tautologically, because what exists must be fit by definition." Having initially run into the same problem, we sympathize. This situation, however, presents an obvious concern. To what extent should we be comfortable building conceptual schemes upon a construct that we cannot define?

In this section, we attempt to construct a definition of a fitness construct that avoids the tautology problem just identified. We do so through a series of steps:

1. We characterize the contexts where the use of a fitness construct is most appropriate. This is done through defining abstract sets of entities, separated by a period of time, for which the number of member entities can either increase or decrease over time.

2. We present a model where "fitness" plays the role of an unobservable intermediate variable that is determined by an entity's state and leads to an observable value, realized fitness, measured by the ratio of the number of entities in the set at the end of the period divided by the initial number of entities.

3. We explore the concept of a fitness proxy, an observable variable that adapting entities may use in place of fitness when attempting to increase realized fitness.

Throughout this derivation we provide examples that may be helpful in clarifying the concepts being introduced.

\section{FITNESS: THE RELATIONSHIP BETWEEN INITIAL AND FINAL SET COUNTS}

In proposing our own approach to defining fitness, our goal was to remain as faithful as possible to its biological counterpart. In biology, fitness consists of two key elements: survival and reproduction. Both of these can be presented in terms of a set, the population, for which two membership counts can be taken, separated by a specified period of time- often referred to as a generation. The duration of a generation will normally be determined by taking into account the nature of the entities. For example, if you were to study certain periodic cicadas, you would need to recognize that a dormancy period of 17 years exists between the disappearance of one brood and the emergence of its progeny. Between those two events, the population would essentially be zero. Therefore 17 years would be an appropriate duration for a generation and multiples of 17 years would be needed if an accurate sense of population growth or decline were to be achieved.

The nature of the set and duration selected would also determine the degree to which survival, reproduction or both are emphasized. For example, in the cicada example the reproduction process dominates entirely. If we were to look at another set of entities, such as the violins made by Antonio Stradivari, we have a set whose membership is constrained, since he ceased making violins by the mid- $18^{\text {th }}$ century. Thus, if we were to track that set's membership over time, we would be looking strictly at the survival aspect of fitness. The sets and durations we define can also combine both survival and reproduction. For example, if we were to look at the fitness of a particular city in terms of its population set, our "survival" process — which looks at what happens to the original membership of the set-would be negatively impacted by deaths and individuals moving out. Our "reproduction" process, referring to members of the final set not present in the original set, would be positively impacted by births and individuals moving in.

The earlier Stradivari example also illustrates how a context can be established for looking at the fitness of artifacts, not just biological entities. In fact, framing fitness-appropriate contexts in terms of before and after sets puts relatively few limitations on its applicability. It is its flexibility that makes fit- 
ness particularly relevant to informing science. If we define our sets in terms of the number of individuals holding a particular idea, we can consider the "fitness" of a particular idea or belief, a concept deriving from the notion of a meme (Dawkins, 1976). We might also use fitness-once we have defined it - as a basis for comparing alternative informing approaches. In this example, we might choose a number of before and after sets of individuals, each of which would experience a different informing intervention intended to convey a particular concept. A ratio of the number of individuals who have acquired that concept after each intervention over the number who had already acquired the concept prior to a particular intervention could then be established. These ratios could be interpreted as the fitness of each intervention (generation) and could be compared. Alternatively, we could take the ratio of individuals still holding their original beliefs after and before each intervention. These could be interpreted as a fitness measure of the original beliefs - with smaller values being indicative of an effective intervention.

To further generalize the contexts in which fitness might be appropriate, we can consider adapting our before and after set counts. Allowing fractional membership is one approach. Using a biological example, if you were trying to define sets to trace the survival and reproduction of a particular individual's set of genes, you might approximate it with the following fractional memberships:

- $50 \%$ membership to the individual's children,

- $25 \%$ membership to each of the individual's grandchildren,

- $12.5 \%$ membership to the individual's great-grandchildren and so forth.

In this example, the "and so forth" will not go on forever. Eventually, the individual's lines are likely to intersect on both the male and female sides. This would make the determination of what constitutes a set more complicated, but does not impact the underlying ability to frame the problem at issue in fitness terms.

Another type of generalization would be to allow weighted assignment to sets based on the presence of specific attributes in each entity. This approach is particularly applicable to design and design science (Gill \& Hevner, 2013). In the world of IT, for example, a particular artifact tends to become obsolete within a relatively short time-indeed, we use the biological term "generations" to refer to this ongoing process of technology evolution. Despite this evolutionary process, particular features of a design may persist considerably longer. For example, the PS/2 keyboard and mouse port continued to be incorporated into personal computers for a couple of decades after IBM's ill-fated line of PS/2 computers was abandoned. To determine before and after set counts appropriate for determining fitness, we could choose a weight $\left(\mathrm{w}_{\mathrm{i}}\right)$ for each characteristic feature $\left(\mathrm{c}_{\mathrm{i}}\right)$. Assuming there were $\mathrm{N}$ artifacts in a particular set, the count at any given point in time would be specified by:

$$
\sum_{i=1}^{N} w_{i} * \text { Number of entities having characteristic } c_{i}
$$

\section{THE FITNESS MODEL}

Once we have established a generational context for which initial and ending counts can be established, we can then turn to defining fitness itself. The most obvious approach would be to use a unitless (non-absolute) comparative measure, such as the ending/initial count ratio or the percentage difference between the two sets (e.g., (ending-initial)/initial). Unfortunately, this approach to defining fitness leads to a number of conceptual problems:

- The tautology problem identified earlier, in which any element of the ending set must be "fit" by definition (McCarthy, 2004, p. 131).

- Fitness cannot be determined for any set without initial members; this would be particularly troubling in applying fitness concepts to areas such as informing and design. To build on our earlier example, if we look at the fitness of an instructional intervention in terms of the relative presence or absence of the understanding of a concept before and after an intervention, the ratio is undetermined if none of the before set already understands the concept. 
- Once fitness is defined as a ratio, the ratio itself is not fitness but in fact a comparison of relative achievement of fitness and it does not make sense to ask what fitness depends upon-since we already know.

In spite of these problems, we find that the simplicity of this measure nevertheless makes it attractive in the vast majority of plausible cases. Rather than calling the ratio fitness, however, we will refer to it as realized fitness. To address the zero initial count problem, there are a number of approaches we might take. In the context of informing, as suggested by the earlier example, one approach would be to take the ratio of those entities not in the set of interest (e.g., who do not understand the concept in the prior example) at the end and divide it by those not in the set at the beginning. Inverting this ratio would offer a measure somewhat comparable to realized fitness. Where this type of inverse derivation also fails (e.g., the ending set has no members), we might assign some arbitrary value, such as the number of members in the final set, in order to calculate realized fitness.

Having defined a variable that we can actually measure, we can then define fitness itself as the expected value of realized fitness across all possible scenarios (including interventions and generations), weighted by the likelihood of each scenario occurring. Defined in this manner, we can propose the fitness model presented in Figure 1.

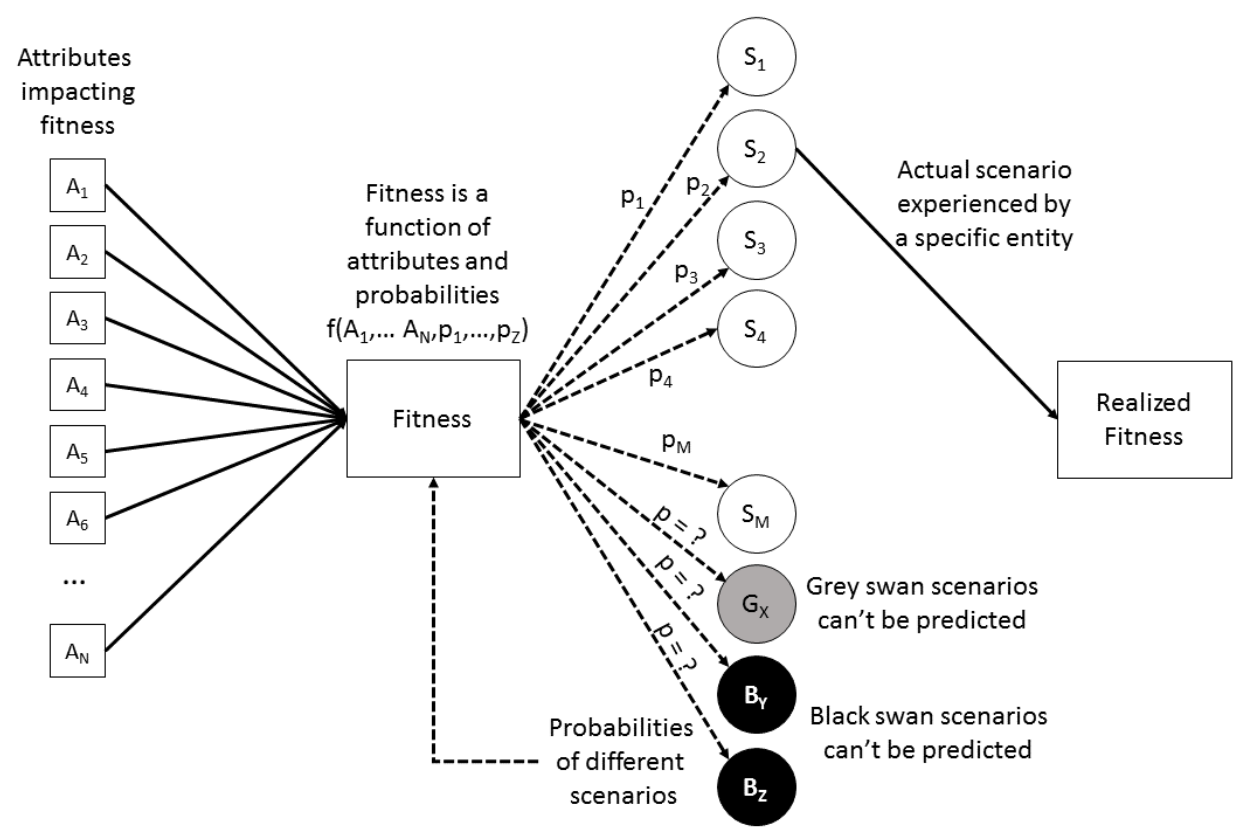

Figure 1. Fitness predicts realized fitness across the weighted probabilities of all possible scenarios

In this model, fitness can be characterized as a function of:

- a collection of $\mathrm{N}$ attributes $\left(\mathrm{A}_{1}, \ldots, \mathrm{A}_{\mathrm{N}}\right)$, determined by an entity's state,

- the probabilities for all possible scenarios that could occur once an entity's state has been selected

Realized fitness will then depend upon which of that series of possible scenarios actually occurs. M of those scenarios $\left(\mathrm{S}_{1}, \ldots \mathrm{S}_{\mathrm{M}}\right)$ represent outcomes whose probabilities $\left(\mathrm{p}_{1}, \ldots \mathrm{p}_{\mathrm{M}}\right)$ might actually be determined or estimated. Other scenarios, however, may occur whose likelihood and impact will defy all attempts at prediction or quantification. These states can be referred to as grey swans and black swans (after Taleb, 2007): 
- Grey swans, in this sense, would represent unpredictable events that are a consequence of

complex interactions within the system of interest itself. Ending states like the "bursting" of financial bubbles, for example, occur from time to time but nevertheless seem to surprise everyone when they occur.

- Black swans, on the other hand, represent unpredictable events whose origins fall outside of the system being examined. Taleb uses the colorful example of a particular casino that, in attempting to assess all possible risks, failed to account for the possibility that a tiger might end up chewing up one of the performers leading to a measurably lower state of fitness at the end and nearly bankrupting the casino.

Since we have defined fitness as the expected value across all scenarios and have also asserted that the probabilities and impact of the two swans cannot be predicted, it follows that true fitness is unknowable. The best that we can hope for is to develop a reasonably accurate estimate of fitness for those scenarios that we can predict and include_-perhaps_-an allowance for attributes promoting adaptability that will facilitate our ability to survive (or exploit) those events that we cannot predict.

As we have defined fitness, if we were to keep repeating the same period over and over again, each repetition independent of the last, then our average realized fitness would eventually converge to fitness itself. The same might apply if we have a very large collection of entities where the likelihood of a particular scenario is independently determined for every entity. We refer to the set of states that determine whether an entity is or is not included in that large collection as a state-set. Such a state-set can itself be treated as a landscape, representing a portion of the main landscape in which certain attributes are restricted to a set of allowable values.

Taleb (2007) presents evidence that: 1) unpredictable swan events play a far more important role in determining outcomes than is generally recognized, and 2) grey and black swan events often have a major impact precisely because they violate the assumption that individual outcomes within and across systems are uncorrelated. These characteristics place significant limits on our ability to estimate fitness. Moreover, even if we could get a perfect estimate of fitness, realized fitness would often depart from that value - sometimes by a great deal. Having survived and thrived for hundreds of millions of years, we can reasonably assume that the true fitness of dinosaurs was quite highprobably very close to 1.0 if we are using the ratio of ending count to starting count (i.e., stable). Assuming that the prevailing scientific wisdom is correct, however, all it took was a single black swan event—an asteroid — to all but wipe them out.

\section{FITNESS PROXIES}

The obvious problem with fitness, as just defined, is that true fitness is unknowable. Moreover, in order to model it we would need repeated measures of realized fitness for different combinations of the attributes that impact fitness. Sometimes, in simple cases, that approach will work well. Tools such as multiple linear regression or logistic regression can be used to separate out the impact of individual attributes on a fitness-related dependent variable, producing a compact fitness model. As we shall soon see, however, the presence of high levels of extrinsic complexity will make building such a model nearly impossible. That seems to make true fitness a construct that we can neither observe nor predict with any accuracy. Not the best formula for a useful construct.

The inability to observe or measure fitness directly is particularly problematic when dealing with entities that have the capacity to change state intentionally, such as human decision makers. In the long run, it is essentially tautological to assert that the best choices an entity can make will be those that maximize its overall realized fitness. And, where the overall success of a "species" (entity) across generations is concerned, the realized fitness of its progeny.

In the context of human decision-making, evolutionary economists argue that utility, the construct that economists use for the internal function that determines our preferences between states, must necessarily have evolved towards making choices that enhance our fitness (Galdolfi, Gandolfi \& Ba- 
rash, 2002). In other words, the process through which utility determines individual choices must have-at least over long periods of our past—-tuned our preferences to making fitness-enhancing choices. Individuals and civilizations whose utility functions were not so-tuned would, as a consequence of their lower fitness, decline as a percentage of the total population and, eventually, go extinct.

Survival of the fittest, as just described, probably functions pretty efficiently in an environment where the set of states available to entities are relatively limited and slow to effect change. In this sense, biological evolution has tended to proceed much more slowly than changes to our systems-technologies and lifestyles, for example-in the modern age. As a consequence, many of our choice of states, such as how much to eat when an abundance of food is placed in front of us, may still be tuned to an environment when most scenarios involved scarcity. For this reason, states based solely upon a Darwinian sense of survival may not serve to optimize fitness in today's world.

Given the potential value of knowing true fitness, it is not surprising that we have found substitutes. We refer to any approach or measure that can be substituted for estimating fitness directly as a fitness proxy. To be a good fitness proxy, a construct needs only possess three attributes. First, it should be relatively easy to acquire (measure) for any potential state-set whose mean fitness we wish to estimate. Second, it should offer an ordinal ranking of states. Unlike our earlier definitions of fitness and realized fitness, the units or values of a fitness proxy do not necessarily have to mean anything as long as the measure can be used for purposes of comparison and choice. Finally, there should be some basis for expecting it to be related to fitness or realized fitness.

Fitness proxies abound today. They fall into a variety of categories, some of the most important of which include:

- Expert rankings. Published rankings, for example, may help us choose between different automobiles, universities, hospitals, vacation spots and products on the internet-just to toss out a few examples. The underlying basis for accepting these rankings is the belief that experts, having studied a particular set of comparable state-sets (e.g., individuals whose state includes ownership of a particular automobile) in greater detail and with greater knowledge (expertise), are likely to produce a more accurate estimate of fitness.

- Popularity. The number of users of many different artifacts and services is readily available today, particularly in the online world. Measures of relative popularity, such as market share, also fit this category. The relationship between popularity and fitness is straightforward; as we have defined fitness, long periods of high fitness will lead to continued high realized fitness and, as a consequence, a meaningful increase in membership of the set. Conversely, poor fitness will be evident from a loss of popularity.

- Consensus ratings. Even where raters are not experts, consensus scores-such as the average of reviewer ratings for a restaurant-may be used as a basis for estimating fitness. Like popularity, where strong preferences are expressed by users of an artifact or service, we would expect the consensus to drive the size of the set and its fitness over time.

- Imitation. We may choose to follow the choices of individuals that we perceive to be at higher fitness levels, even when we cannot ascertain their expertise. The underlying assumption here is that where similar choices are available to us-for example, in the type of athletic shoes worn, the beer consumed or the politicians favored - by mimicking their choices entities expect to increase their own fitness similarly.

- Composite proxies. We may take several different proxies and combine them according to our own situation. For example, in making a choice between items we may look at each item's price as a proxy for its value - even knowing that this is a weak relationship at best-and yet, at the same time, also consider what other sources of potential fitness we would need to forgo if we choose the higher priced item. Similarly, it would be rare for a high school student to choose a college strictly based upon its published ranking according to news magazines. 
Other factors indicating fitness, such as location, setting, costs and facilities would likely be considered in tandem with the ranking.

In considering the above list, which is undoubtedly incomplete, we seem to be wandering quite far afield from fitness as defined in biological terms, i.e., survival and reproduction. Indeed, if we were limit our study solely to the realized fitness of different human population groups, we would likely conclude (at the present time) that nature abhors economic development, since those portions of the world that are at or near subsistence are generally reproducing at rates far higher than the more affluent regions.

We would argue, however, that our reliance of fitness proxies, when contrasted with pure instinctive choice, may actually have the effect of bringing utility closer to fitness. This is particularly true where we look at the applications of fitness to sets of artifacts, activities and ideas where adapting agents are involved. The basis of this argument, illustrated in Figure 2, is as follows:

- Fitness proxies, such as those described above, tend to be based upon cumulative realized fitness (e.g., popularity, consensus) or are likely to drive individuals to particular entities in the set of choices (e.g., expert rankings, imitation), thereby increasing the realized fitness of those entities. In either case, these proxies tend to encourage the development or continuation of high realized fitness for those favored entities.

- Because we incorporate those fitness proxies into our utility function, these proxies impact the choices we make. Because we are referring to the choices of a population as a whole, this will inevitably impact the basket of scenarios that occur during each period. If we assumefor convenience's sake - that our basket contains all possible scenarios that could occur, this effect can be assumed to act on the probabilities of each scenario.

- Because the fitness function depends not only upon the state the entity selects but also upon the probabilities of different scenarios, the impact of our utility-driven choices on these probabilities means that our utility indirectly impacts fitness.

It is worth taking a few moments to think about how the occupancy of a set of states might impact the fitness of the set. Suppose a specific state-set contains a finite amount of some needed resource-either renewable or non-renewable. If too many agents are attracted to that state-set as a result of its popularity proxy, or if agents linger too long on the state-set, the resources may become exhausted. That would change the fitness of that state negatively. On the other hand, if a state-set is subject to a network effect-meaning the more members of the set, the greater its value per member-a change in the opposite direction can occur. For example, if the set consists of agents using a particular communications system (several examples of online social networking information systems come to mind), the more agents joining that set, the more valuable that system becomes to its member entities. The fitness of each state in the set therefore increases (even if not all entities participate in the system at the same individual level of fitness).

As presented in Figure 2, there are a couple of potential feedback loops. The first is the very slow fitness-driven evolutionary process described by economists, in which:

- Utility drives our choices, with very limited impact on the probabilities of different postchoice scenarios.

- Realized fitness, in the form of survival, rewards and punishes different utility functions.

- Over time, natural selection causes surviving utility functions to correspond closely to fitness. Because this process will tend to produce changes very slowly (i.e., over many generations), in the short run we can refer to fitness in this model as static. It also closely parallels fitness as used in evolutionary biology and as it is adapted for the management and strategy literatures (e.g., Frenken, 2006; Leventhal, 1997; Porter \& Siggelkow, 2008) 


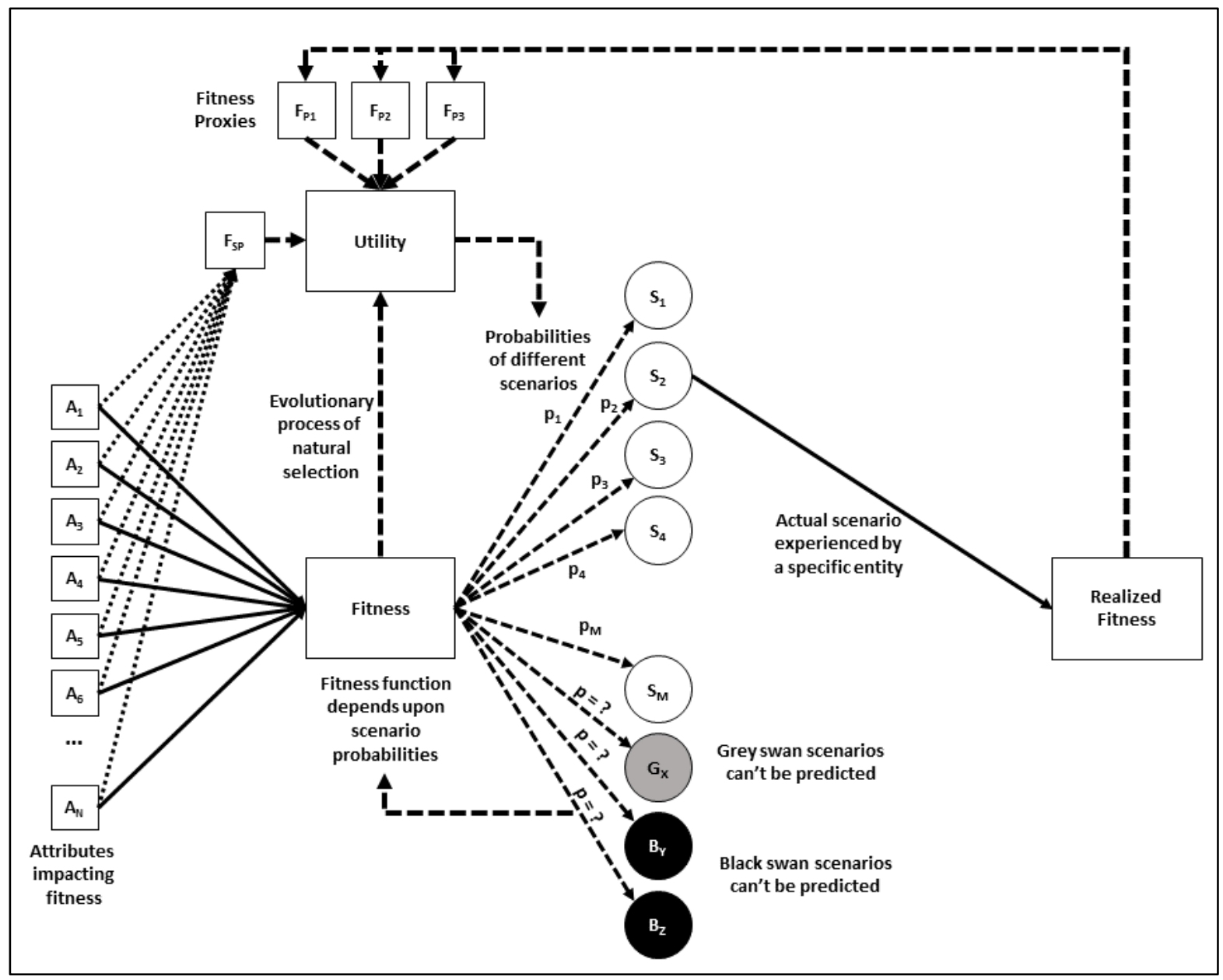

Figure 2: The potential feedback loops that develop when fitness proxies are used to guide choice

The second feedback loop occurs much more rapidly:

- Realized fitness influences some of the fitness proxies we use $\left(\mathrm{F}_{\mathrm{P} 1} \ldots \mathrm{F}_{\mathrm{P} 3}\right.$ in the example diagram)

- These proxies influence utility; we would expect one or more proxies to incorporate some or all of the same attributes that contribute to fitness independent of popularity ( $F_{S P}$ in the diagram), the type of fitness that we earlier characterized as static fitness. For example, if we were talking about a product and fitness was being assessed in terms of the set of units being sold, $\mathrm{F}_{\mathrm{SP}}$ might be reflective of factors such as relative cost, design, quality and technological superiority.

- Utility determines our decisions, thereby influencing the probabilities of different scenarios

- Probability changes influence realized fitness, which influences the popularity-based proxies that we use, and so forth...

Because fitness is defined to be our expected value for realized fitness, it "comes along for the ride" in the second process; it is very dynamic. The impact of static fitness on utility is so slow, however, that it does not play a major role in the process. The static fitness of the first process may be influential very early in the process - impacting the survival and reproduction of the original entities to occupy the state-set. Once the process gets going, however, the fitness proxies we choose are more likely to be the main drivers of fitness. In effect, the map (proxies) becomes the territory (fitness). An- 
other potential way to consider this static/dynamic effect is that the two feedback loops actually occur over different generational timespans making the first impactful only after significant multiples of generations that occur in the second feedback loop.

In fact, general systems theory suggests that the second (dynamic) loop might produce a number of dynamic behavior patterns measured by entity occupancy (Gill, 2016a). These include:

- Negative feedback: The effects of state-set occupancy upon static fitness are sufficiently negative that as soon as capacity is reached, agents will tend to abandon it. The result is that occupancy will remain within a narrow band, like the behavior of temperature governed by a thermostat.

- Periodic cycling: Where negative feedback is present but its impact on realized fitness is subject to a significant time delay, a system may fall into a regular periodic cycle, where occupancy goes up and then goes down regularly.

- Chaotic cycling: With come combinations of parameters, such as those seen in the chaotic region of the logistic function, occupancy might cycle irregularly across a range of values-a process highly sensitive to initial conditions. This type of function is sometimes used to model population levels in predator-prey systems (Devaney, 1989).

- Positive feedback: Increases in occupancy produce ever growing increases in realized fitness that produces a cascade of agents moving to the state-set. As described earlier, states subject to network effects can exhibit these behavior, which can also produce bubbles.

Economists have identified many examples of the positive feedback driven by the second (dynamic) loop occurring in real life. Perhaps the most well-known was the competition between VHS and Betamax for dominance in the video cassette market (Arthur, 1988). For a few years, the two formats competed head-to-head. At a certain point, however, VHS started to develop a slight lead in sales. Once consumers recognized that this lead existed (i.e., employing market share as a fitness proxy), a sudden and dramatic shift to VHS occurred and the Betamax format was abandoned. All this occurred despite Betamax's generally acknowledged slight technological superiority over the VHS format (i.e., FSp may well have been slightly higher for Betamax).

As illustrated by the prior example, our fitness proxies do not necessarily reflect the values that we claim to prize most, such as quality or privacy for example. Even worse, the measures that tend to make for easy-to-acquire proxies_-such as existing popularity — naturally tend to promote feedback loops in which popular state-sets become even more popular (i.e., the rich get richer). Nevertheless, over and over again evidence suggests that entities use easy to acquire proxies in place of systematic attempts to estimate fitness. And in doing so, we further amplify their effects even as we condemn them. We see this in the academic world all the time. As members of the university community, we recognize the innate illogic of university rankings. Yet a surprising fraction of our efforts seem to be directed towards improving our own institution's performance according to these dubious metricsreinforcing their importance. In every sense then, realized fitness is directly related to the actual choices made and is not determined by theoretical more or less logically or "ideal" choices. To understand why such paradoxical behaviors may be inevitable, we need to understand how complexity impacts the relationship between the attributes that define a state and fitness (both static and dynamic).

\section{EXTRINSIC COMPLEXITY}

We use the term fitness landscape to describe the mapping of all possible states to their associated fitness. Most commonly, this relationship is presented in a form where a particular scenario is assumed for each state or where the probabilities of different scenarios are assumed to be constant, in which case the fitness function can be expressed as:

$$
\text { Fitness }=\mathrm{f}\left(\mathrm{A}_{1}, \ldots, \mathrm{A}_{\mathrm{N}}\right)
$$




\section{DEFINING EXTRINSIC COMPLEXITY}

The nature of the assumed function $\mathrm{f}$ can vary considerably. For our purposes, the extrinsic complexity of a fitness landscape can be expressed in terms of the minimum amount of information necessary to model the relationship between attributes of all possible states and their associated fitness to a desired degree of precision. This is similar to the concept of Kolmogorov complexity (Li \& Vitany, 1993) as applied in computer science. Our rather dense definition may be somewhat clarified through some examples.

\section{Example 1: Simple additive fitness}

Suppose we have a state space whose individual states can be described with $\mathrm{N}$ attributes, $A_{1}, \ldots, A_{N}$. Further suppose that we can define $\mathrm{N}$ transformations, $\mathrm{x}_{1}\left(\mathrm{~A}_{1}\right), \ldots, \mathrm{x}_{\mathrm{N}}\left(\mathrm{A}_{\mathrm{N}}\right)$, abbreviated as $\mathrm{x}_{1}, \ldots, \mathrm{x}_{\mathrm{N}}$, that capture the impact of each attribute on the expected fitness of each state across the attribute's entire range of values. The simple additive fitness model could be expressed as:

$$
\text { Fitness }=\mathrm{x}_{1}+\mathrm{x}_{2}+\ldots+\mathrm{x}_{\mathrm{N}}
$$

The $\mathrm{x}_{1}, \ldots, \mathrm{x}_{\mathrm{N}}$, transitions might be of a very simple nature, such as $\mathrm{c}_{1 *} \mathrm{a}_{1}, \ldots, \mathrm{c}_{\mathrm{N}} * \mathrm{a}_{\mathrm{N}}$ (the standard linear regression equation model) or might involve a more complex relationship, such as an inverted " $U$ " transformation for variables that make their greatest contribution to fitness when balanced between too little and too much.

What makes this model "simple" is that regardless of how many allowable states can be defined, the information required to determine fitness depends entirely on the amount information needed to describe the $\mathrm{N}$ transformations $\mathrm{x}_{1}, \ldots, \mathrm{x}_{\mathrm{N}}$. In other words:

\section{Extrinsic complexity $\propto \mathrm{N}$}

In the linear regression model, for example, that amount of information would be the theoretical minimum number of bits required to store $\mathrm{N}+1$ real numbers at the desired level of precision. Furthermore, it will always be possible to maximize expected fitness by maximizing the contribution of each attribute independently. Stated another way, in this landscape the value of fitness is fully determined by summing the independent main effects for every variable.

\section{Example 2: Simple multiplicative fitness}

A simple multiplicative model closely parallels the simple linear model., The difference is that elements are multiplied-producing percentage rather than absolute changes in fitness for each attribute- rather than being added, i.e.,:

$$
\text { Fitness }=\mathrm{x}_{1} * \mathrm{x}_{2} * \ldots * \mathrm{x}_{\mathrm{N}}
$$

In this model, we see the same properties regarding the maximum and the expected number of peaks. Also, by taking the logarithm of the relationship, it transforms to an additive model. In the logarithmic model, 0 (the logarithm of 1 for all bases) becomes the steady state case, positive values indicate increases in counts, while negative values indicate declines in counts.

\section{Example 3: Maximum extrinsic complexity}

Suppose we have a state space whose individual states can be described with $N$ attributes, $A_{1}, \ldots, A_{N}$. Further suppose that there are $\mathrm{M}$ possible states, defined by all the legal possible combinations of values for $A_{1}, \ldots, A_{N}$ and that no discernable pattern exists for assigning fitness to each combination. Then the extrinsic complexity of the expected fitness function will be proportional to the number of possible states M. Assuming each attribute can take on J possible values, this simplifies to:

$$
\text { Extrinsic complexity } \propto \mathrm{M}=\mathrm{J}^{\mathrm{N}}
$$

This number can become very large. For example, if each attribute can take on just two values $(J=2)$ and there are 20 attributes $(N=20)$, then $M$ is over a million $\left(2^{20}\right)$. This compares with determining 
just 20 coefficients (plus a constant) if expected fitness follows the simple linear model. Of particular importance, the effect of changing a particular attribute $A_{i}$ cannot be determined without knowing the values of all remaining N-1 attributes. Stated another way, in this landscape, fitness is entirely determined by interactions between attributes; combinations_- not individual values — are the only thing that are important.

\section{FITNESS LANDSCAPES AND PEAKS}

In visualizing the fitness functional relationship, the notion of a fitness landscape is often invoked. On that landscape, each state has its own fitness value - corresponding to its altitude. Multiple entities may exist in any given state. That state is surrounded by states that are adjacent. Adjacency in this context occurs when an entity in an "adjacent" state can transition to the state with a single affected action or procedure. In cases where the fitness of a particular state is higher than that of all adjacent states, we have a peak. That peak is always a local maximum. It may also be the global maximum across the entire fitness landscape.

Peaks play a particularly important role in determining the expected behavior of entities on a fitness landscape. Nearly any model of presumed behavior on a fitness landscape is based on the assumption that entities on that landscape continue to transition from state to state in the search for higher fitness. Once an entity reaches a peak, however, none of the adjacent transitions available will lead to increased fitness. Therefore many models assume that the entity will cease searching at that point. The drawback of this type of search is that where a landscape has many local peaks, the entity may get stuck occupying a state whose fitness is lower than can be found in other regions of the landscape and never pursue a global maximum state.

\section{Peaks and extrinsic complexity}

We have defined extrinsic complexity in terms of the amount of information required to describe the relationship between state attributes and fitness. We could have almost as easily defined it in terms of the number of local peaks expected to occur on that landscape. We can illustrate this relationship by comparing the previous examples of simple and maximally complex relationships between attributes and fitness.

\section{Low extrinsic complexity single peak}

Referring back to Example 1, the simple additive model, fitness was determined by the sum of $\mathrm{N}$ attributes, transformed, if necessary, by functions $\mathrm{x}_{1}, \ldots, \mathrm{x}_{\mathrm{N}}$ to capture their individual and independent impacts on fitness, i.e.,

$$
\text { Fitness }=\mathrm{x}_{1}+\mathrm{x}_{2}+\ldots+\mathrm{x}_{\mathrm{N}}
$$

This relationship will have one and only one peak provided that two other assumptions also hold true:

1. Each function $x_{i}$ does not produce multiple local peaks across its range. In mathematical terms, the transformation $x_{i}$ is monotonic over the entire domain of $A_{i}$ or has a single peak over that domain.

2. Each state attribute value $A_{i}$ can be set independently of other state values.

That peak will occur where every attribute value $A_{i}$ is chosen so that it maximizes the value of $x_{i}\left(A_{i}\right)$. For example, if the transformation consists of a simple regression coefficient, i.e., $x_{i}\left(A_{i}\right) \equiv c_{i}{ }^{*} A_{i}$, then $x_{i}$ will be maximized for the highest value of $A_{i}$ across its range if $c_{i}$ is positive, and the smallest value of $A_{i}$ across its range if $c_{i}$ is negative. Search is greatly simplified by the fact that the value for each $A_{i}$ can be selected without concern about interactions with the other attributes.

The second assumption, being able to set attributes independently, is needed to avoid situations where a particular value of $A_{i}$ cannot be reached unless certain other attributes, such as $A_{j}$ and $A_{k}$, 
have specific values. For example, if $A_{i}$ represents a career choice and its peak fitness value is for a cardiac surgeon, that state value may not be reachable without $A_{j}$ (e.g., graduate degree) being set to medical degree and $A_{k}$ (e.g., residency specialty) having been set to cardiac surgery. This opens the possibility of other local peaks being available to individuals not having the necessary prerequisites.

\section{High extrinsic complexity peaks}

At the other extreme, the maximally complex Example 3, no simple formula can be devised to capture the functional relationship between attributes and fitness. In fact it is the large amount of information needed to capture that relationship that defines extrinsic complexity. It may be possible, however, to estimate the number of peaks on such a landscape if some additional information is acquired. We begin by noting that we assume that there is no pattern to the relationship between states and, therefore, expected fitness occurs where all states have an equal possibility of being local peaks. So, if we choose an arbitrary state, its likelihood of being a peak is the same as the likelihood that it is the largest value in the set consisting of itself and however many adjacent states are present. If we assume that the average number of adjacent states is A, we can express that likelihood as:

$$
1 /(\mathrm{A}+1)
$$

Earlier, we assumed M possible states. Since the same likelihood applies to all M states, the expected number of peaks becomes:

$$
\mathrm{M} /(\mathrm{A}+1)
$$

This number can get very large under conditions of high extrinsic complexity, since $\mathrm{M}$ tends to grow combinatorically with the number of attributes. In the previous Example 3, we considered a scenario where each attribute could take on two values and state was defined by 20 attributes. If we continue making the assumption that each state attribute can be set independently, then a particular state has 20 adjacent states. The formula for the number of local peaks then becomes:

$$
\left(2^{20}\right) /(20+1) \approx 50,000
$$

This example segues nicely into one of the most commonly used approaches to simulating fitness landscapes.

\section{Kauffman's NK landscapes}

There is no "right" way to construct simulated landscapes that capture extrinsic complexity. Common to model building activities in general, there will typically be a tradeoff between the simplicity of the model and the number of aspects we wish to incorporate into that model. Increasing the number of aspects being modeled invariably increases the number of parameters that the modeler must estimate (or, more often, guess) values for. Eventually, a model is produced that is so flexible that it can support any conclusion that the modeler cares to draw.

In modeling the impact of extrinsic complexity on agent behavior, a particularly widely used model is Kauffman's (1993) NK landscape. Its principle virtue is its remarkable simplicity-requiring only two parameters:

1. N: The number of attributes impacting fitness

2. K: The number of interacting variables determining how a particular attribute impacts fitness, ranging from 0 (each variable effects fitness only through its main effect; this corresponds to the earlier Example 1 Simple additive relationship) to N-1 (the impact of a particular attribute on fitness can be determined only by knowing the value of every other attribute; this corresponds to Example 3 Maximally complex relationship).

How the basic NK model can be implemented is described in many places (e.g., Gill, 2012, p. 80-83). For our purposes here, it is sufficient to note that: 
- All attribute values are binary (0 or 1$)$, which eliminates any concern about multiple local peaks within a particular variable's range.

- Adjacent states are assumed to be those states whose pattern differs by only 1 attribute value. Thus, any particular position on the landscape always has $\mathrm{N}$ adjacent states. This is equivalent to saying that a decision-making entity always has $\mathrm{N}$ possible choices to consider, no matter where it exists on the landscape.

- Fitness is defined as an ordinal value that does not directly correspond to survival or reproduction levels as the model is typically implemented. As such, the "fitness" value assigned to each state would be better characterized as a fitness proxy, using our terminology.

- No feedback between realized fitness and actual fitness is implemented; fitness values set by the model generally remain constant throughout a particular simulation run.

As a consequence of these assumptions, the NK model is most commonly employed to look at how changing extrinsic complexity influences an entity's search for fitness. Specifically, as the K parameter varies from 0 to its maximum value of $\mathrm{N}-1$, extrinsic complexity —as we have defined it-rises accordingly. Implications of that rise are summarized in Table 1.

\section{EXTRINSIC COMPLEXITY AND DYNAMIC FITNESS}

A significant drawback of NK landscapes and other attempts to simulate landscape complexity is their static nature. Given our proposed definition of fitness (i.e., the expected value of realized fitness) this is a serious deficiency. If we are looking at entities, the realized fitness of a state for a particular entity will largely be determined by the degree to which that state attracts new entities. Since fitness proxies based on the popularity of a state are common, a static model fails to account for the impact of realized fitness-based proxies feeding back to influence fitness itself, such as those illustrated earlier in Figure 2. For decision-making entities, this would suggest the model might need an occupancy-based fitness proxy to supplement the static attribute-based fitness proxy already assumed by the NK model.

Table 1: Key findings from Kauffman (1993) regarding structure of NK landscapes as $\mathrm{K}$ increases

\begin{tabular}{|c|c|c|}
\hline Finding & Description (page) & Interpretation \\
\hline I & $\begin{array}{l}\text { The number of local peaks increases (p. } \\
60 \text { ) }\end{array}$ & \multirow{3}{*}{$\begin{array}{l}\text { The likelihood of encountering a low peak } \\
\text { and, potentially, becoming trapped on it, } \\
\text { grows. At the same time, high extrinsic com- } \\
\text { plexity increases the likelihood that a high fit- } \\
\text { ness peak exists within a given distance of an } \\
\text { arbitrary position on the landscape. }\end{array}$} \\
\hline II & $\begin{array}{l}\text { The mean fitness of peaks declines (p. } \\
56 \text { ) }\end{array}$ & \\
\hline III & $\begin{array}{l}\text { The mean distance for a random entity } \\
\text { to the nearest peak declines (p. } 57 \text { ) }\end{array}$ & \\
\hline $\mathbf{T}$ & $\begin{array}{l}\text { Local peaks become more uniformly } \\
\text { distributed across the landscape (p. } 62 \text { ) }\end{array}$ & $\begin{array}{l}\text { Combinations that produce high fitness will } \\
\text { become increasingly diverse in nature. }\end{array}$ \\
\hline $\mathbf{V}$ & $\begin{array}{l}\text { States adjacent to a particular state be- } \\
\text { come less correlated (p. } 63 \text { ) }\end{array}$ & $\begin{array}{l}\text { As the average difference in fitness between } \\
\text { adjacent states grows, the likelihood of experi- } \\
\text { encing large fitness increases or declines over } \\
\text { the course of a search for higher fitness grows. }\end{array}$ \\
\hline & $\begin{array}{l}\text { Correlation falls off rapidly as the dis- } \\
\text { tance between states increases. }\end{array}$ & $\begin{array}{l}\text { An agent observing other entities is increasing- } \\
\text { ly likely to gain useful insights into fitness only } \\
\text { from its closest neighbors. }\end{array}$ \\
\hline
\end{tabular}

The potential value of having entities observe other entities in their search for higher fitness was demonstrated in research (Gill, 2012, p. 61) that looked at how landscape ruggedness impacted tendency towards homophily, which is the tendency of entities to seek out and establish groups of selfsimilar entities. In simulations of 100 entities searching an NK landscape of substantial complexity, a 
number of alternative search strategies for simulated agents were compared. The most effective strategy, by far, was a goal-seeking approach where agents acquired and retained information by observing nearby agents. Among its benefits:

- Higher average static fitness at the end of the run (when all agents has reached peaks)

- Fewer average steps to reach a final peak

- Higher cumulative static fitness over the course of the search process

The group employing this search strategy also ended up occupying a much smaller percentage of peaks than agents employing other search strategies, such as random walks. This result provided support for the conclusion that high extrinsic complexity tends to encourage homophily. Where such a behavior is present, however, we would necessarily expect that popularity play a major role in determining occupancy.

Incorporating dynamic fitness changes into the NK simulation model is beyond the scope of this paper. In our opinion, doing so would be unlikely to yield compelling results in any event. The problem is that modeling the feedback loop described in Figure 2 would require adding numerous assumptions regarding the relative importance of different types of proxies, how the utility function of agents on the landscape would be constructed, how to generate realistic scenarios and estimate their probabilities, how to determine generation duration, and so forth. In doing so, the key benefit of the NK landscape model—its simplicity—would be undermined.

What we can do, however, is to look at the effects presented earlier in Table 1 and offer reasoned arguments as to how such feedback is likely to influence them. In Table 2, our conclusions and rationale regarding the likely influence of popularity-driven fitness proxies on Table 1 behaviors are summarized.

Table 2 phenomena IX and $\mathrm{X}$ together will tend to produce the familiar punctuated equilibrium (Bak, 1996) that is observed in many complex adaptive systems. Peaks gaining in occupancy will tend to be sticky as a consequence of their popularity-driven proxies. Also, the risk of moving off a peak rises with extrinsic complexity (a result of $\mathrm{V}$ in Table 1). These factors will make the system as a whole seem very stable. But, as a peak's occupancy reaches a high percentage of available agents, its ability to maintain high rates of growth declines. At that point, there is an opening for a new high fitness state to gain in popularity, producing a rapid increase in realized fitness. That gain may be attractive enough to pull some agents from the original peak. Their departure will, in turn, generate a drop in the realized fitness and corresponding proxies for the original state. This could set up a positive feedback loop that precipitates further departures and further drops, producing a very rapid transition of many agents to the new state. The rapidity of this phenomenon, for example, is a central element of the behavior pattern described in the "innovator's dilemma" (Christensen, 1997). In Christensen's well-known model, the formerly loyal and enthusiastic customers of an existing supplier abruptly change to a new supplier once a disruptive technology's price-capabilities set achieves a particular threshold. Examples of the phenomenon described by Christensen included the U.S. steel industry, the computer storage industry, and the minicomputer industry.

Phenomena such as the one described can be characterized as information cascades (Gill, 2010). They occur when rapid transitions from one state to another occur as a consequence of agents observing the behavior of other agents. The cumulative graph of the transition frequently follows the familiar S-curve of the diffusion of innovations (Rogers, 2003). In many of the models for this type of process, a diversity of agent behaviors exist (Gill, 2008). An innovator agent, for example, is presumed to be far less attached to any given peak than the typical agent. Early adopters carefully monitor the successes and failures of innovators, regular adopters keep an eye on the experiences of regular adopters, and so forth. When looking at the aggregate behaviors across state-sets, rather than for individual states, evolutionary theory provides a basis for expecting heterogeneity to be present. The concept of an evolutionary stable strategy (ESS; Maynard Smith \& Price, 1973), derived from game theory, shows how a mix of different strategies within a population can achieve equilibrium. 
Table 2: How popularity driven fitness proxies are expected to influence static fitness NK landscape behaviors

\begin{tabular}{|c|c|c|}
\hline Finding & $\begin{array}{l}\text { Effect contrasted with expected } \\
\text { behaviors on a static landscape } \\
\text { of comparable extrinsic com- } \\
\text { plexity }\end{array}$ & Rationale \\
\hline VII & $\begin{array}{l}\text { The number of observed fitness } \\
\text { peaks that are occupied will be } \\
\text { lower. }\end{array}$ & $\begin{array}{l}\text { Agents will be drawn to peaks with high occupancy, } \\
\text { and will spend less time exploring for new peaks. }\end{array}$ \\
\hline VIII & $\begin{array}{l}\text { Peak occupancy will diverge con- } \\
\text { siderably from normal (Gaussian) } \\
\text { and will be more likely to resemble } \\
\text { a power law. }\end{array}$ & $\begin{array}{l}\text { A similar feedback-driven phenomena has been ob- } \\
\text { served in traffic through internet routines (Barabasi, } \\
\text { 2002; Watts, 2003). Indeed, power laws are com- } \\
\text { monly observed wherever "rich-get-richer" forces } \\
\text { exist (Gill, 2010). }\end{array}$ \\
\hline IX & $\begin{array}{l}\text { Peaks with increasing occupancy } \\
\text { will become very attractive to } \\
\text { agents. }\end{array}$ & $\begin{array}{l}\text { An agent's willingness to seek out a new peak from } \\
\text { an existing peak will depend on the perception that } \\
\text { fitness of the new peak is higher. Fitness proxies } \\
\text { that trigger from increasing occupancy will tend to } \\
\text { make a peak in its ascendency seem very high fit- } \\
\text { ness. }\end{array}$ \\
\hline $\mathbf{X}$ & $\begin{array}{l}\text { When a peak begins to be aban- } \\
\text { doned in favor of another peak, } \\
\text { the process will occur much faster } \\
\text { where dynamic fitness processes } \\
\text { dominate. }\end{array}$ & $\begin{array}{l}\text { The complement to IX, if agents begin leaving one } \\
\text { peak for another, the popularity-based fitness prox- } \\
\text { ies will drive the period-to-period realized fitness of } \\
\text { the original peak down quickly. }\end{array}$ \\
\hline $\mathbf{X I}$ & $\begin{array}{l}\text { Agent reliance on fitness proxies } \\
\text { will increase with extrinsic com- } \\
\text { plexity. }\end{array}$ & $\begin{array}{l}\text { As underlying complexity grows, both lack of suffi- } \\
\text { cient exemplars and cognitive processing limitations } \\
\text { will require agents to employ simplifying strategies; } \\
\text { ultimately states that maximize proxies may become } \\
\text { the new "peaks". }\end{array}$ \\
\hline XII & $\begin{array}{l}\text { Groups of agents will seek con- } \\
\text { sensus on a limited number of } \\
\text { fitness proxies, and will seek to } \\
\text { incorporate fitness proxies of self- } \\
\text { similar agents. }\end{array}$ & $\begin{array}{l}\text { As proxies increasingly come to define peaks on } \\
\text { high extrinsic complexity landscapes (XII), } \\
\text { knowledge of proxies used by agents in nearby } \\
\text { states will become essential in locating nearby peaks. }\end{array}$ \\
\hline
\end{tabular}

\section{INFORMING AS A SEARCH FOR HIGHER FITNESS}

Interestingly, the potential payback for exploratory behaviors is likely to grow under high extrinsic complexity (Table 1, I) even as dynamic complexity produces attraction to highly occupied nonadjacent peaks. We can hypothesize that these two competing forces will tend to increase the observed turbulence on a landscape as its extrinsic complexity grows.

Within the informing science transdiscipline, the search for higher fitness has been used as a model of the informing process. This process can be viewed from two lenses, the client's (entity's) and the informer's.

\section{THE CLIENT PERSPECTIVE}

When viewed from the client's perspective, the informing process can be thought of as a transition through fitness states over time, as illustrated in Figure 3. Originally based on a static fitness model, it was assumed that a client reaching a local fitness peak would remain at a relatively constant level of 
fitness (i.e., a plateau), and the process of acquiring new knowledge would initially lead to a decline in fitness - as the original knowledge state was disrupted - that would then transition to a new fitness state that would, hopefully, be higher than the original state. Two additional factors make the process far from straightforward, however. These factors can be characterized as three different aspects of the complexity of the informing task (Gill, 2016a):

1. Experienced complexity: There may be considerable uncertainty regarding the relative fitness of the original and target states, as suggested by the cloud in the diagram. The client may also be concerned about the perceived difficulty of the transition. Both describe psychological states in the mind of the client, commonly referred to as experienced complexity (Campbell, 1988).

2. Intrinsic complexity: The transitions that must be undertaken to move between the two states may be complicated. This is a direct result of the particular approach that the client adopts, or expects to adopt, to make the transition. It has been referred to under a variety of names, including objective complexity (Wood, 1986), problem space complexity (Gill \& Hicks, 2006) and simply as task complexity (Haerem, Pentland \& Miller, 2015). For our purposes, we adopt the term intrinsic complexity to distinguish those aspects of the task that are performer-specific vs. those that are driven by the environment.

3. Extrinsic complexity: As already defined, the term characterizes the underlying shape of the relationships between state attributes and survivability.

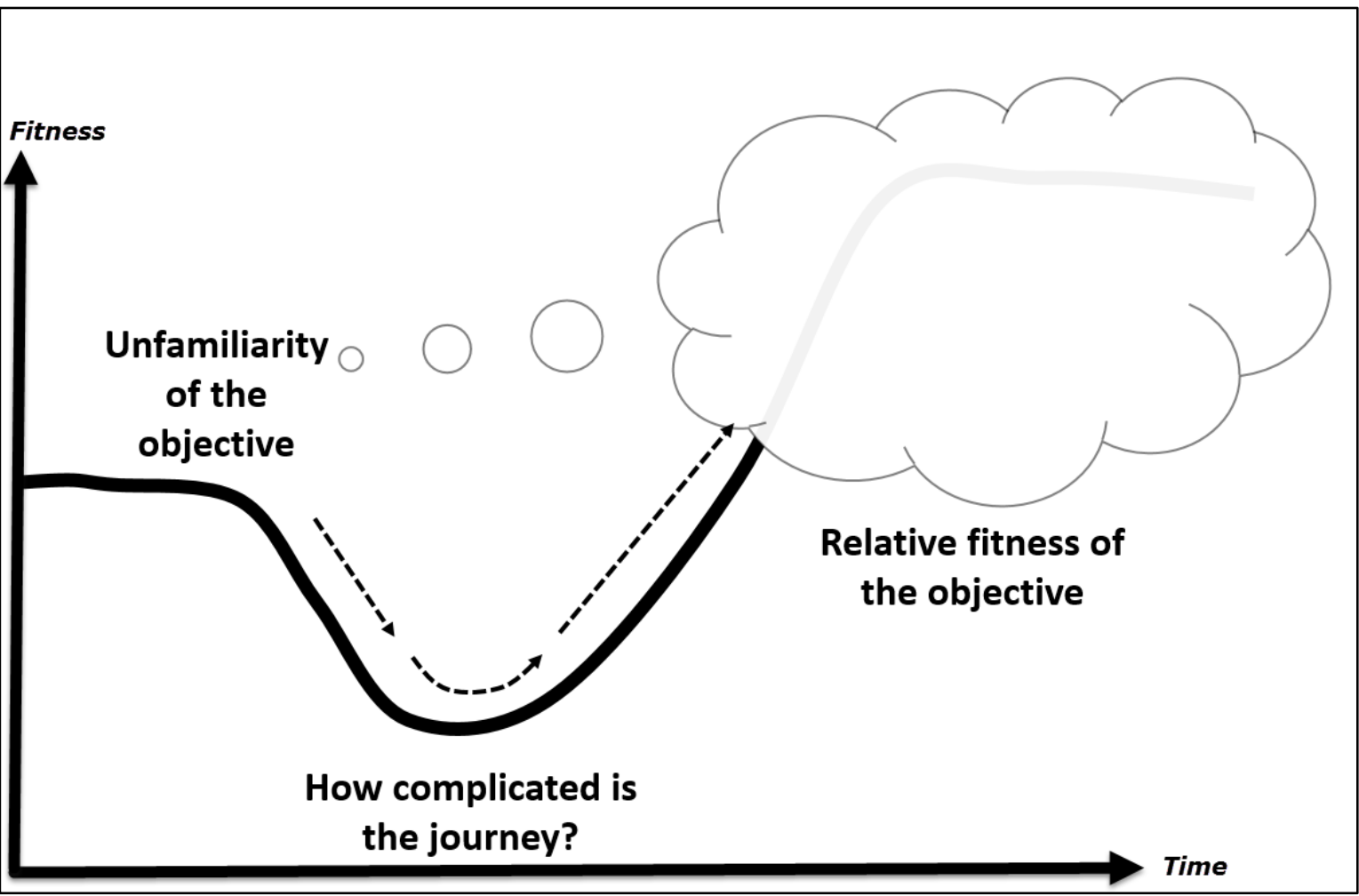

Figure 3: Fitness from the client perspective, presented as changes in fitness over time (from Gill, 2016a, p.151)

For the purposes of the present paper, we concentrate on the last of these. We would, however, to expect any informing process to be influenced by all three forms of complexity and the interactions between them. For example, high extrinsic complexity could increase the client uncertainty with respect to the fitness of a particular state (experienced complexity) and the expected ruggedness of the landscape could impact the client's approach to reaching the target (intrinsic complexity). 


\section{Incorporating extrinsic complexity and dynamic fitness}

An increase in extrinsic complexity is likely to have three impacts on the Figure 3 model. First, it will make it harder for the client to assess the fitness of an individual state. Second, it will—under most circumstances-make the cost of traversing the fitness valley between to peaks harder to estimate. Finally, it will be harder to determine the potential fitness increase that can be acquired by transitioning between states. In this landscape, movement between typically non-adjacent peaks requires more than one affected action or process when seeking a higher state of fitness. The anticipated effects from Table 1 and Table 2 can be used to make qualitative predictions with respect to how this might change the client's informing process. Among the most likely impacts:

- Clients will tend to migrate towards a relatively small number of highly occupied and competing knowledge states (Table 2, VII). As an example, consider scientific paradigms. In those domains where a "right" answer is presumed to exist and can be tested-e.g., many of the physical sciences - a single dominant paradigm will most likely flourish, a consequence of the low extrinsic complexity of such domains. A dominant paradigm will only be displaced by a more successful dominant paradigm; effectively, this is the process described in Kuhn's (1970) scientific revolution. In those domains where the adequacy of knowledge is much harder to assess and where interaction effects dominate-i.e., high extrinsic complexity domains - we would expect many local fitness peaks (Table 1, I-III). In a static fitness model, we would expect many of these to be occupied over time. In the dynamic fitness model, however, a relatively small number of these will emerge as coexisting paradigms that vigorously compete for adherents, occupied by the vast majority of clients (Table 2, VIII). A paradigm that does not continually gain adherents will eventually be viewed as passé, and adherents may abruptly transition to other perspectives (Table 2, X).

- Clients will increasingly rely on fitness proxies to estimate the fitness of knowledge states (Table 2, XI). Popularity and, especially, popularity growth (e.g., "buzz"), will be particularly influential in determining what knowledge states clients choose to occupy (Table 2, IX). Easy to acquire proxies that capture popularity (e.g., view counts, best seller lists) and peer rankings will become increasingly influential in decisions to seek a particular knowledge state.

- Clients will seek opportunities to interact and align themselves with self-similar individuals in order to acquire locally relevant information about potential knowledge state targets (Table $1, \mathrm{~V}-\mathrm{VI})$; general expertise, in turn, will become suspect. The clusters formed through this process will tend to adopt similar fitness proxies (Table 2, XII). We would, for example, expect that such a process would naturally lead to the development of knowledge silos and the formation of groups that hold wildly dissimilar views with respect to how the world operates (Table 1, IV).

In the broadest sense, under very high levels of extrinsic complexity we would expect that the peerbased effects described in Table 2 will come to both dominate and amplify the static complexity effects of Table 1. In many ways, this could be characterized as a trade-off between different types of informing task complexity. The higher the extrinsic complexity, the greater the reliance on a "simple" approach (imitation) to choosing and moving between states.

\section{An example: Use of social media to become informed}

Extrinsic complexity, particularly as it relates to Table 2 effects, might provide an explanation for changing patterns for how individuals become informed. Just as an example, consider the question of why social media grows in importance as a source of political informing for each succeeding generation, as illustrated by a Pew Research study shown in Figure 4. The logic here is as follows:

- A number of forces, most notably globalization and technology development, tend to increase the extrinsic complexity of the environment (Gill, 2010), providing individuals with many more possible states to which they could transition. 
- This impact is likely to be most significant for individuals less habituated to a particular fitness state, i.e., earlier in their career.

- For such individuals, opportunities to acquire knowledge from self-similar peers will be particularly valuable when contrasted with information from general experts. Hence, these networks have become the dominant information source for both Generation X (51\%) and the Millennials (61\%; Mitchell, Gottfried \& Matsa, 2015, p. 11).

- Such opportunities, however, will also be valuable to individuals in older generations (e.g., the $39 \%$ of baby boomers that gather political information from Facebook); it is just that the relative value will be slightly less. Indeed, because they are more habituated to a particular fitness state, they will be more likely to seek out content that supports their existing knowledge state. For example, boomers are much more likely to see posts largely in line with their own views (31\% of the time; Mitchell, Gottfried \& Matsa, 2015, p. 11) than Generation $\mathrm{X}(21 \%$ of the time) and the Millennials (18\% of the time). Nevertheless, the percentage of each group that rarely sees posts in line with their own views is nearly identical $(12 \%$ for boomers; $12 \%$ for Generation X; $14 \%$ for Millennials), suggesting that this is not purely a generational difference in desire to avoid cognitive dissonance.

\section{Among Millennials, Facebook Far Exceeds Any Other Source for Political News}

$\%$ who got news about politics and government in the previous week from...
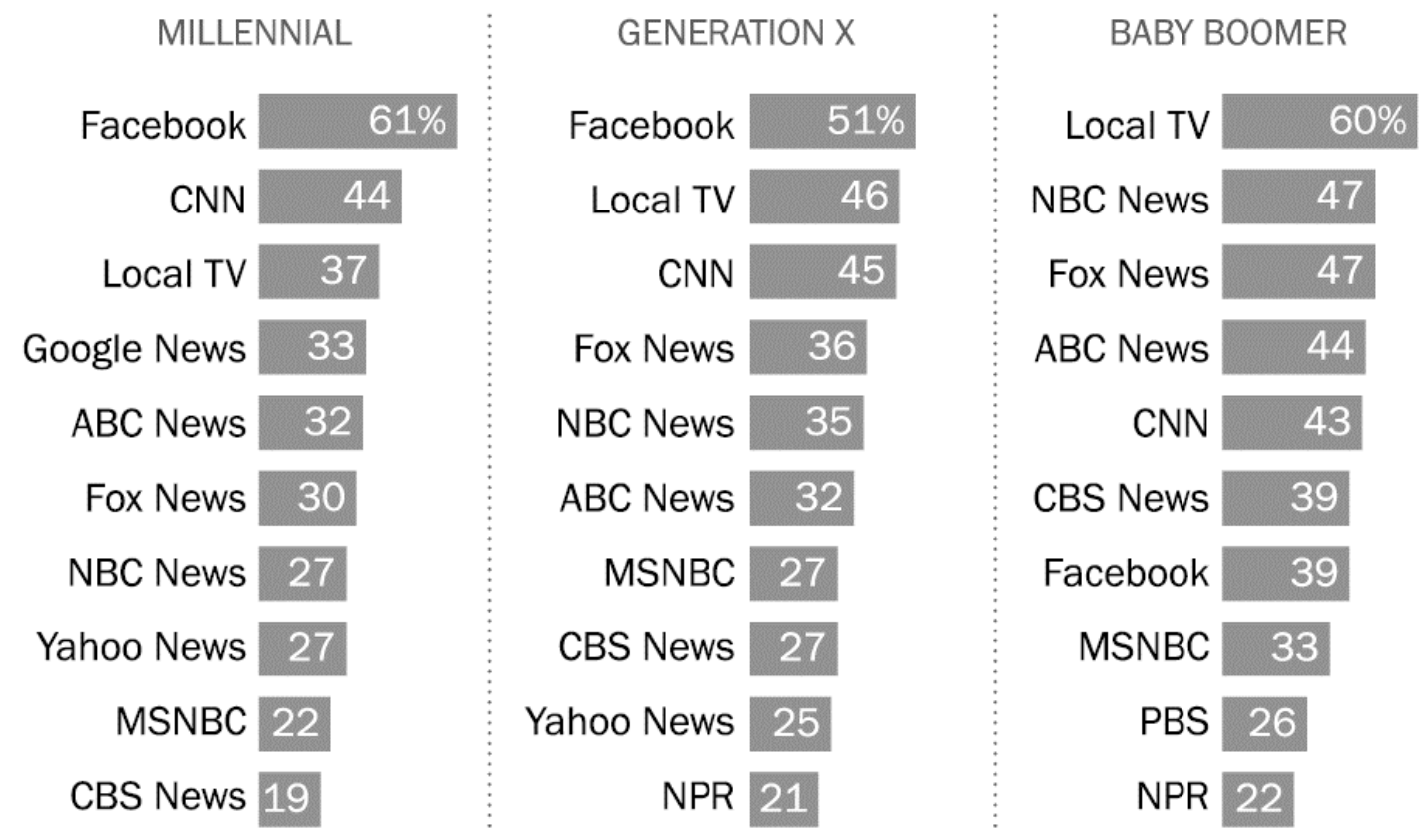

American Trends Panel (wave 1). Survey conducted March 19-April 29, 2014. Q22, Q24A. Based on online adults.

PEW RESEARCH CENTER

Figure 4: The role of social media in sourcing political news by generation (Mitchell, Gottfried \& Matsa, 2015; p. 8) 


\section{THE INFORMER PERSPECTIVE}

The informing task from the perspective of the informer has also been examined through the lens of fitness. In this scenario, the informer must address the fitness question from two dimensions:

1. The possible initial states from which the client or collection of clients starts.

2. The possible target states that could be the consequence of the informing process.

Supposing each initial and target state represents a real or perceived fitness peak, the informing process might be viewed conceptually as shown in Figure 5. The $\mathrm{X}$ axis signifies the number of initial client states (either for multiple clients and/or situations where an individual's initial state is unknown). The $\mathrm{Y}$ axis signifies the number of possible target states that would constitute successful informing. Where that number is 1, we may presume that only one "right answer" as an informing outcome. Where multiple target states exist, multiple states-possibly quite different in naturecould be considered outcomes for a successful informing process. The latter situation would be typical where the informing occurs in high extrinsic complexity environments.

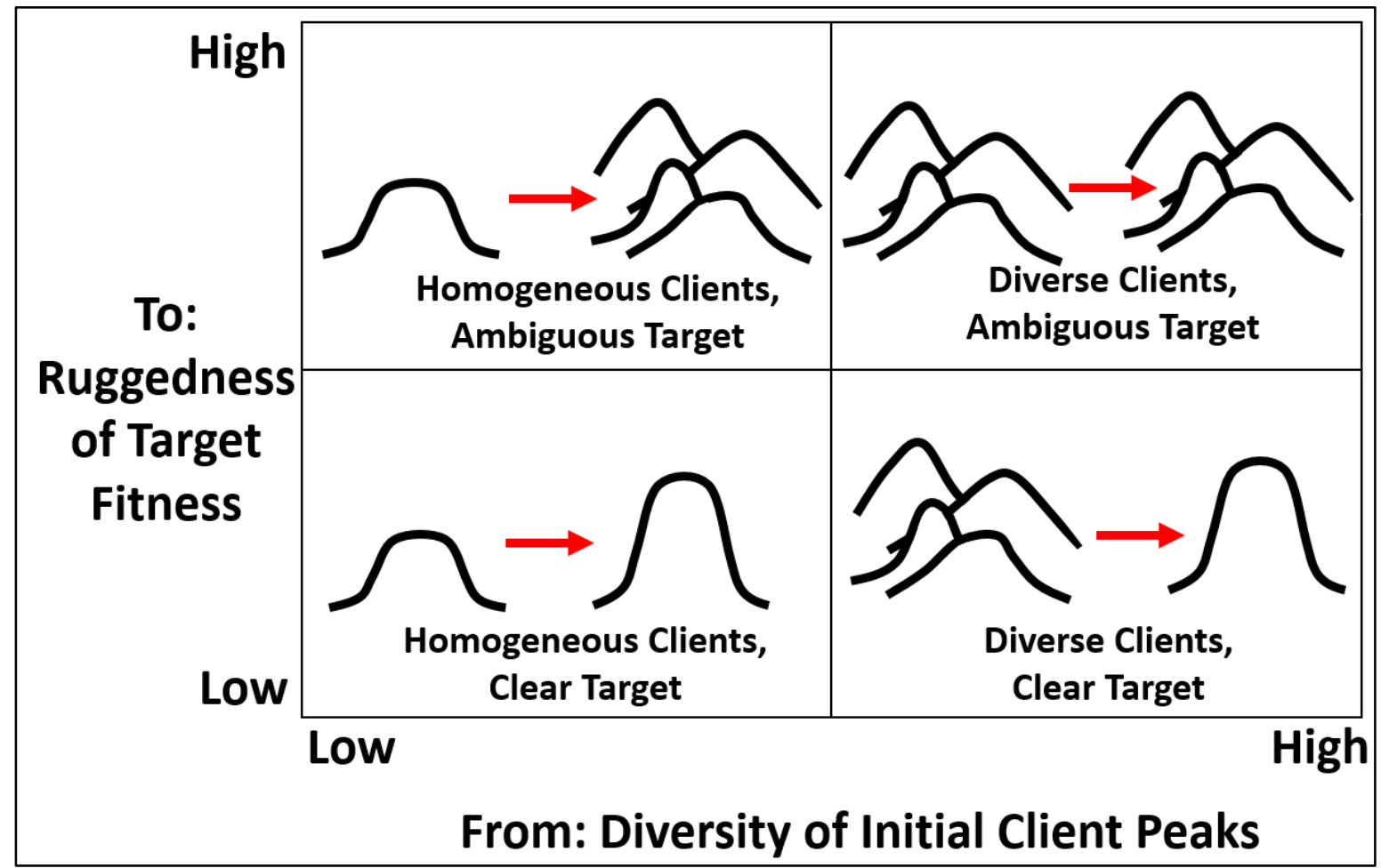

Figure 5: Possible scenarios in the informing task from the informer perspective (Murphy, Murphy, Buettner, \& Gill, 2015, p. 69)

Regardless of whether or not dynamic fitness processes are considered, Figure 5 highlights a key informing challenge: the number of paths between initial state and target that the informer must consider in presenting content. Assume, for example, that $\mathrm{M}$ starting states and $\mathrm{N}$ target states are present. In the case where $\mathrm{M}$ is 1 (i.e., no client diversity), only 1 (bottom left quadrant) or $\mathrm{N}$ (top left quadrant) possible paths must be considered. Similarly, where $\mathrm{N}$ is 1 (a right answer exists) only 1 (bottom left quadrant) or $\mathrm{M}$ (bottom right quadrant) paths must be charted. The really troublesome case is where $\mathrm{M}>1$ and $\mathrm{N}>1$ (top left quadrant), in which case $\mathrm{M} \times \mathrm{N}$ paths are possible. In this case, the conclusion reached was as follows:

Of necessity, the clients themselves will need to be heavily engaged in mapping out their own learning paths, any formally designed system that efficiently moves clients along a sensible path would quickly become too complicated to sustain itself (Gill, 2016b, p. 91). 
Unfortunately, in high extrinsic complexity environments, we can expect this challenging quadrant to be encountered with ever-greater frequency, since both clients and target peaks will tend to spread out across a landscape (Table 1, IV) of increasing extrinsic complexity.

\section{Incorporating extrinsic complexity and dynamic fitness}

An increase in extrinsic complexity is likely to impact three of the four quadrants of the Figure 5 model. When compared with a pure static fitness model having the same number of peaks, we would expect the inclusion of dynamic fitness to produce greater clustering around peaks (Table 2, VII). This would have two impacts:

1. Reducing the number of distinct client types

2. Increasing the tendency of clients to choose between a limited subset of possible target peaks

Both effects would seem to suggest that the process of identifying appropriate informing paths for clients should become less complicated in a dynamic model as opposed to a pure static model. The caveat here is that the assumption of high extrinsic complexity means that we are already presenting ourselves with so many paths as to challenge our cognitive limits and clients are pressed to take multiple actions to move to potentially higher peaks.

Incorporating dynamic complexity would likely transform the group dynamics of the informing process. In the pure static complexity model, individuals might look at their peers for cues, leading so some homophily (e.g., Gill, 2012). In the dynamic complexity model, this phenomenon would be amplified. Individuals might well choose to replicate behaviors and proxies adopted by individuals perceived to be similar to themselves, leading to clusters of participants who follow very similar paths towards the same target (Table 2, XII). In such an environment, the informer's strategy would necessarily need to adapt in order to be effective. For example, interventions that are directed towards a single individual would likely prove ineffective. Not only would the informer have to address the challenge of motivating the client to initiate the transition (i.e., Figure 3), he or she would also need address the strong tendency to revert to the group norms of the individual's associated cluster.

For large client groups, the presence of high extrinsic complexity might also produce greater volatility in actual informing outcomes than would otherwise be predicted. Suppose, for example, you were the instructor in a series of course sections that each had 100 students. Where each of the students attending the class chose their own target and path independently, you would expect that the variation in informing outcomes from section to section would not be terribly great-much as you would expect the number of heads and tails to be reasonably similar if you flipped a fair coin 100 times. If, however, the same 100 students self-organized into a small number of groups, each of which established its own patterns of behavior and fitness proxies, we would expect the variability between sections to be much greater, even as the variability between participants within a section might decline by virtue of group formation. Even where only static fitness is modeled, homophily can emerge and the replicability of successive trials tends to be low (Gill, 2012). Adding the tendency to self-organize predicted by the dynamic fitness model will lead to even greater variability.

\section{CONCLUSIONS}

In the present paper we have argued that our understanding of informing processes can be advanced by a clearer understanding of what is meant by fitness and environmental complexity. In doing so, we have chosen to present possible definitions for two key concepts:

1. Fitness: the expected value of the growth or shrinkage in the membership a set of entities over s specified interval.

2. Extrinsic complexity: the amount of information required to capture the relationship between the attributes that define a particular entity's state and that state's associated fitness. 
What we have subsequently argued is that understanding extrinsic complexity has profound implications for informing. Specifically:

- Because extrinsic complexity is driven principally by the level of interaction between attributes in determining fitness, high extrinsic complexity implies a landscape with many local fitness peaks.

- Many local fitness peaks, in turn, produces a number of interesting implications. These include:

- The potential risk of encountering very sharp fitness changes (either drop-offs or increases) when exploring the landscape rises; where clients are risk averse, this may increase their tendency to cling to an existing peak (i.e., retain their current knowledge state).

- The likelihood of deriving useful information from observing the realized fitness of neighboring agents drops off dramatically as their attributes begin differ from those of the observer; informing benefits will therefore arise from grouping with selfsimilar agents (i.e., homophily), the consequences of whose behaviors are likely to be far more representative of what the agent itself will experience.

- The likelihood of becoming stuck on a relatively low local fitness peak increases; in the informing context, this suggests increased likelihood of becoming trapped in knowledge states that are far less valid than other states.

- The diversity of potential knowledge states that lead to high fitness will increase; a particular local peak may be governed by rules that seem entirely different from those of a distant (non-adjacent) peak; knowledge therefore becomes increasingly localized.

- With high extrinsic complexity, it becomes increasingly unlikely that generalizable principles for achieving fitness will be available owing to the amount of information required. That implies:

- An agent will become increasingly dependent upon proxies in its search for fitness; a proxy is any individual or composite value that is perceived likely to reflect underlying fitness (e.g., rankings, popularity scores).

- Venues that offer insights into popularity-based fitness proxies-particularly where similar agents can find each other-will be prized as a source of information; social networks and online shopping venues are two obvious examples of these.

- Where a popularity-based proxy is widely accepted, a feedback loop is established whereby fitness itself is impacted by the population shifts motivated by the proxy. Depending upon the context, different impacts may be observed. These include negative feedback (e.g., the old joke, "that restaurant has really gone downhill, it has become way too crowded"), positive feedback (e.g., the network effect for social media applications), or some type of cycling (e.g., the logistic function sometimes used to model population dynamics).

- The twin forces of increased attachment to a particular local peak and the increased reliance on fitness proxies make it likely that high extrinsic complexity will be accompanied by both environmental turbulence brought about by changing fitness and information cascades, where formerly stable trends change very quickly.

From the informer's perspective, when dealing with groups of clients that are not part of a homophilic small world, there is a very strong likelihood that the group will:

- Start from a very diverse set of initial states.

- Will be seeking a very diverse set of target states over the course of the informing process.

To accommodate this diversity, we believe that client-centric approaches to informing that facilitate individual path discovery will increasingly need to be devised and employed. Future research that ex- 
plores and proposes such techniques seems to be a particularly good fit for the informing science transdiscipline. As the current paper suggests, the very nature of extrinsic complexity makes it resistant to silos. Only a research philosophy that encourages crossing disciplinary boundaries seems to offer the prospect of advancing our understanding of such informing contexts.

\section{REFERENCES}

Arthur, W. B. (1988). Self-reinforcing mechanisms in economics. In P. W. Anderson, K. J. Arrow, \& D. Pines (Eds.), The economy as an evolving complex system (pp. 9-32). Reading, MA: Addison Wesley.

Bak, P. (1996). How nature works: The science of self-organized criticality. New York: Copernicus.

Barabasi, A. L. (2002). Linked. New York, NY: Plume.

Beinhocker, E. D. (1999). Robust adaptive strategies. Sloan Management Revien, 40(3), 95-106.

Campbell, D. J. (1988). Task complexity: A review and analysis. Academy of Management Review, 13, 40-52.

Christensen, C. (1997). The innovator's dilemma. New York, NY: HarperCollins.

Dawkins, R. (1976). The selfish gene. Oxford, UK: Oxford University Press.

Devaney, R. L. (1989). An introduction to chaotic dynamical systems (2nd ed.). Redwood City, CA: Addison-Wesley.

Frenken, K. (2000). A complexity approach to innovation networks. Research Policy, 29, 257-272.

Frenken, K. (2006). A fitness landscape approach to technological complexity, modularity, and vertical disintegration. Structural Change and Economic Dynamics, 17, 288-305.

Gandolfi, A. E., Gandolfi, A. S., \& Barash, D. (2002). Economics as an evolutionary science: From utility to fitness. New Brunswick, NJ: Transaction Publishers.

Gill, T. G. (2008). Resonance within the client-to-client system: Criticality, cascades, and tipping points. Informing Science: The International Journal of an Emerging Transdiscipline, 11, 311-348. Retrieved from https://www.informingscience.org/Publications/450

Gill, T. G. (2010). Informing business: Research and education on a rugged landscape. Santa Rosa, CA: Informing Science Press.

Gill, T. G. (2012). Informing on a rugged landscape: Homophily versus expertise. Informing Science: The International Journal of an Emerging Transdiscipline, 15, 49-91. Retrieved from https://www.informingscience.org/Publications/1560

Gill, T. G. (2016a). Informing science, volume 1: Concepts and systems. Santa Rosa, CA: Informing Science Press.

Gill, T. G. (2016b). Informing science, volume 2: Design and research issues. Santa Rosa, CA: Informing Science Press.

Gill, T. G. \& Hevner, A. (2013). A fitness-utility model for design science research. ACM Transactions on Management Information Systems, 4(2), Article 5.

Gill, T. G., \& Hicks, R. (2006). Task complexity and informing science: A synthesis. Informing Science: The International Journal of an Emerging Transdiscipline, 9. 1-30. Retrieved from https://www.informingscience.org/Publications/469

Haerem, T., Pentland, B. T., \& Miller, K. D. (2015). Task complexity: Extending a core concept. Academy of Management Review, 40(3), 446-460.

Kauffman, S. A. (1993). The origins of order. Oxford, UK: Oxford University Press.

Kuhn, T. S. (1970). The structure of scientific revolution (2nd ed., enlarged). Chicago, IL: University of Chicago Press.

Levinthal, D. (1996). Learning and Schumpeterian dynamics. In G. D. Malerba (Ed.), Organization and strategy in the evolution of the enterprise. Basingstoke, UK: Macmillan Press Ltd. 27-41.

Levinthal, D.A. (1997). Adaptation on rugged landscapes, Management Science, 43(7), 934-950. 
Fitness, Extrinsic Complexity \& Informing Science

Li, M. \& Vitanyi, P. (1993). An introduction to Kolmogorov complexity and its applications. New York, NY: Springer Verlag.

Maynard Smith, J., \& Price, G. R. (1973). The logic of animal conflict. Nature, 246(5427), 15-18.

McCarthy, I. P. (2003). Technology management -- A complex adaptive systems approach. International Journal of Technology Management, 25(8), 728-745.

McCarthy, I. P. (2004). Manufacturing strategy: Understanding the fitness landscape. International Journal of Operations \& Production Management, 24(2), 124-150.

McCarthy, I. P., \& Tan, Y. K. (2000). Manufacturing competitiveness and fitness landscape theory. Journal of Materials Processing Technology, 107(1-3), 347-352.

McKelvey, B. (1999). Self-organization, complexity, catastrophe, and microstate models at the edge of chaos. In J. A. C. Baum, \& B. McKelvey (Eds), Variations in organization science in honor of Donald T. Campbell (pp. 279307). Thousand Oaks, CA: Sage Publications.

Mitchell, A., Gottfied, J., \& Matsa, K.E. (2015). Millennials \& political news. Pew Research Center. June, 1-28. Retrieved from http://www.journalism.org/files/2015/06/Millennials-and-News-FINAL-7-27-15.pdf

Murphy, W. F., Murphy, S. S., Buettner, R. R., Jr., \& Gill, T. G. (2015). Case study of a complex informing system: Joint interagency field experimentation (JIFX). Informing Science: the International Journal of an Emerging Transdiscipline, 18, 63-109. Retrieved from https://www.informingscience.org/Publications/2289

Porter, M. \& Siggelkow, N. (2008). Contextuality within activity systems and sustainability of competitive advantage, Academy of Management Perspectives, 22(2), 34-56.

Reuf, M. (1997). Assessing organizational fitness on a dynamic landscape: An empirical test of the relative inertia thesis. Strategic Management Journal, 18(11), 837-853.

Rogers, E. M. (2003). The diffusion of innovations (5th ed.). New York, NY: Free Press.

Taleb, N. (2007). The black swan. New York, NY: Random House.

Watts, D. (2003). Six degrees: The science of a connected age. New York, NY: Norton.

Wood, R. E. (1986). Task complexity: Definition of the construct. Organizational Behavior and Human Decision Processes, 37, 60-82.

\section{BIOGRAPHIES}

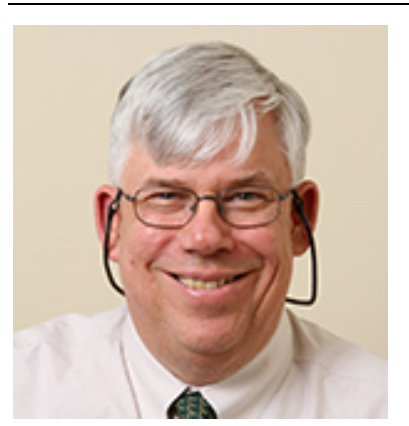

Grandon Gill is a professor in the Information Systems and Decision Sciences department of the University of South Florida. He is also the Academic Director of the Doctor of Business Administration program at the Muma College of Business. He is Editor-in-Chief of the Journal of IT Education: Discussion Cases, also serving as a Governor and Fellow of the Informing Science Institute. In 2014, he was the inaugural recipient of the Zbigniew Gackowski Award for contributions to informing science research. 


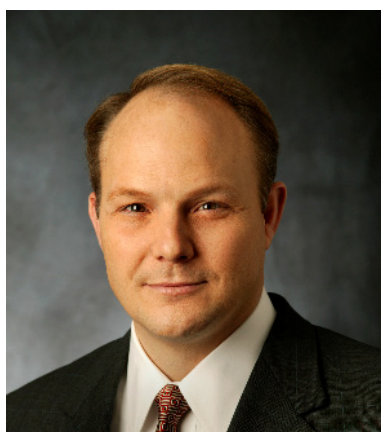

Matt Mullarkey is the Director, Doctor of Business Administration Program at the USF MUMA College of Business and an Instructor in the Information Systems and Decision Sciences department at the University of South Florida. He holds a Ph.D. in Business Administration (Information Systems) from USF, a BS, Engineering, from the United States Military Academy, an MS, Systems Management, from the University of Southern California, and an MBA from the Moore Business School, University of South Carolina. Matt has more than 25 years of experience as President, CEO, COO, and SVP in the automotive, applied materials and medical device industries with P\&L responsibilities globally. His principal research interest are the impact of social networking in and between organizations, monetization of companies' data streams, and applying the case method to MIS and MBA education. He is an editor for the Journal of IT Education: Discussion Cases. 